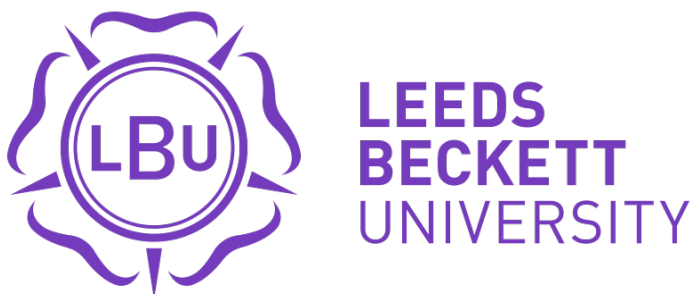

\section{Citation:}

Lofthouse, RM (2018) Coaching in Education: a professional development process in formation. Professional Development in Education, 45 (1). pp. 33-45. ISSN 1941-5257 DOI: https://doi.org/10.1080/19415257.2018.1529611

Link to Leeds Beckett Repository record:

https://eprints.leedsbeckett.ac.uk/id/eprint/5306/

Document Version:

Article (Accepted Version)

This is an Accepted Manuscript of an article published by Taylor \& Francis in Professional Development in Education on 11/10/18, available online: https://www.tandfonline.com/doi/full/10.1080/19415257.2018.1529611

The aim of the Leeds Beckett Repository is to provide open access to our research, as required by funder policies and permitted by publishers and copyright law.

The Leeds Beckett repository holds a wide range of publications, each of which has been checked for copyright and the relevant embargo period has been applied by the Research Services team.

We operate on a standard take-down policy. If you are the author or publisher of an output and you would like it removed from the repository, please contact us and we will investigate on a case-by-case basis.

Each thesis in the repository has been cleared where necessary by the author for third party copyright. If you would like a thesis to be removed from the repository or believe there is an issue with copyright, please contact us on openaccess@leedsbeckett.ac.uk and we will investigate on a case-by-case basis. 


\title{
Coaching in Education: a professional development process in formation.
}

Professor Rachel Lofthouse, Leeds Beckett University, UK

With thanks to the following coaches, whose conversations this paper is based on; Ruth Whiteside, Jo Flanagan, Rebecca Tickell, Simon Feasey and Lou Mycroft

\section{Published in Professional Development in Education, accepted $9^{\text {th }}$ Sept 2018}

\begin{abstract}
Coaching has been evolving as a form of professional development for teachers and school leaders for several decades, and now exists in many forms. This study focused on the work of six coaches in England, using an adapted focus group approach to discover how they explained and conceptualised the value of their practices. As the coaches' conversations with each other emerged details of the nature of their work, and their reflections on it, were elicited which were analysed thematically while also paying due attention to individual narratives. Although coaching is not easily defined this study demonstrates the significance of relationships and dialogue in coaching and the structures and protocols that support that. It suggests that coaching is suited to helping individuals dealing with authentic challenges, professional interests and dilemmas experienced in complex educational settings, while also acting as a counterweight to some of the consequences of performativity. The study also suggests that coaching may be a valuable means to deploy the expertise of experienced professionals to support an education system exposed to problems of retention of both teachers and school leaders.
\end{abstract}

\section{Introduction}

Coaching in education for professional development takes many forms. There has been a growth in the number of coaches working independently, a growing number of schools allocating staff to internal coaching, and an increase in the number of continuing professional development programmes (CPD) which integrate coaching into the offer for participants (both teachers and school leaders). This new research about coaching is undertaken in England where provision of professional development and teacher education has undergone a significant evolution over the last decade. The traditional roles of both local education authorities, government-led national strategies and universities have diminished in favour of a 'school-led self-improving system', the creation of Teaching Schools, Multi-Academy Trusts and the Chartered College of Teaching and a rapid growth of private companies, charities and consultants working in the field. Coaching is part of this trend; and indeed is now being actively promoted by the Department for Education in England (for example in their response to the Strengthening Qualified Teacher Status consultation, and their Women in Leading in Education Coaching scheme). In this landscape coaching inevitably takes many forms and there is insufficient research relating to its efficacy. There are no nationally approved qualifications or standards for coaches working in educational contexts.

Situated within this complex context this research provides a snapshot of coaching represented through the practices of six individuals who work in the field. The aims of their coaching include to develop teaching quality, to enable inter-professional learning, and to facilitate positive and productive relationships through cultural change in educational communities. Using illustrative 
examples this research helps to establish some of the current trends, challenges and emerging opportunities of coaching as a formative educational process.

\section{Themes from the literature informing this research}

Coaching has been defined in a number of ways, with differences emerging across cultures and when it is compared to other CPD practices. Clutterbuck (2001) classifies coaching in terms of the degree of formality and the extent to which it is undertaken as a passive or active approach. Bloom et al. (2005) acknowledge that 'Coaching is all the rage, yet it enjoys no common definition'. Kennedy (2014) regards coaching as a 'malleable' form of CPD, being an approach which can be used responsively and contingently for different purposes. Research into coaching has suggested that it is a successful form of professional development for impact on student outcomes (Joyce and Showers, 1988) and offers good opportunities for professional development (Veenman and Denessen, 2001). Tschannen-Moran and Tschannen-Moran (2010) describe 'evocative coaching' as tapping into teachers' 'consciousness, connection, competence, contribution and creativity'. As such they suggest that it has the potential to develop teachers' self-efficacy (Bandura, 1997), in that teachers believe that they have the capability to develop their own practices in ways which secure the improvements deemed desirable. Despite this potential Lofthouse and Leat (2013) found that the potential of coaching was often undermined in schools, where strongly performative cultures can be pervasive. Simkins et al (2006) in a study of leadership coaching also note numerous contextual conditions (including time available, commitment, and integration of coaching with other aspects of CPD) as critical in how it is perceived by the participants.

This paper is not concerned with judging or measuring the impact of coaching, nor with providing a new unifying definition of coaching or with further categorising types of coaching. It is focused on coaching as a formative process; which might alter educational practices, influence professional working relationships between teachers and others working in or aligned with educational practices, offer an alternative to other forms of CPD and enhance the self-efficacy of those who participate. A key theme of this paper is the collaborative dualism of coaching, where despite coaches and coachees adopting specific roles in relation to each other, and often only working together through the coaching partnership, much of the productive work is done through dialogue based on curiosity, listening, creating spaces in conversations, the sharing of experiences and expertise and reciprocity. Whitmore (2002) suggests that relationships sit at the heart of coaching, highlighting the need for trust, safety and minimal pressure allowing the coach to act as a 'sounding board, a facilitator, a counsellor, and awareness raiser' (p.40). Lofthouse et al. (2010) recognised co-construction as a professional knowledge sharing process, which leads to new action and an opportunity to review it. Lofthouse and Thomas (2017) recognised that in peer-coaching teacher participants were more likely to enter into co-construction than mentors working with student teachers. This indicates the impact of a power dynamic at play in the working relationship.

Coaching can thus be seen as collaborative work between professionals, and as such might extend the concept of the development of collective efficacy, as in the collective belief of teachers in their ability to positively affect students, which Donohoo (2017) recognises can be developed through enhanced professional learning structures and protocols. It might also be seen as contributing to what Hargreaves and O'Connor (2018a) define as 'collaborative professionalism' which they contrast with professional collaboration. Hargreaves and O'Connor suggest that collaborative professionalism involves ten tenets, which include collective efficacy, collaborative inquiry, collective responsibility, 
joint work and mutual dialogue. There are also potential links between the development of coaching practices and coaching cultures and the emergence of ecological agency (Priestley et al. 2015).

\section{Methods and methodology}

As part of a public event to launch 'CollectivED' a new university research and practice centre in March 2017, the author and five other individuals who work in coaching capacities in educational settings held six conversations. The names of these individuals will be used in this paper with their permission. Each conversation was framed by the overall question, 'why bother with coaching in education?', and was conducted in sequence as shown in Table 1. Apart from the overriding question the only common question was to ascertain each coach's identity and the nature of their work. The conversations followed a path of enquiry deemed appropriate in the moment by the participants. This information was used to help the audience to navigate their way through the chain of conversations. Each conversation was nine minutes long, and they were conducted without interruption, commentary or feedback from other participants or the audience. An open discussion was held with the audience as participants following these conversations, but this has not been analysed in this research. Table 1 also indicates basic information about coaching approaches used by each participant to illustrate the range of coaching included in this research.

\begin{tabular}{|l|l|l|l|}
\hline & $\begin{array}{l}\text { Coach in focus in } \\
\text { conversations 1-6 }\end{array}$ & Key information about their roles and coaching approaches & $\begin{array}{l}\text { Conversation conducted } \\
\text { with }\end{array}$ \\
\hline 1 & Ruth Whiteside & $\begin{array}{l}\text { Ruth is a newly appointed member of the senior leadership } \\
\text { team in a primary school which is deemed to be } \\
\text { underperforming, and is deployed as a coach to support teacher } \\
\text { development in that school. }\end{array}$ & $\begin{array}{l}\text { Rachel Lofthouse } \\
\text { (author) }\end{array}$ \\
\hline 2 & Jo Flanagan & $\begin{array}{l}\text { Jo is an independent Speech and Language Therapist who uses a } \\
\text { video-based coaching approach to support primary and early } \\
\text { years teachers to develop communication-rich pedagogies. }\end{array}$ & Ruth Whiteside \\
\hline 3 & Rebecca Tickell & $\begin{array}{l}\text { Rebecca is employed in a school leadership development centre } \\
\text { and has been developing her own coaching skills through the } \\
\text { Institute of Leadership and Management (ILM) programme for } \\
\text { transformational and developmental coaching. }\end{array}$ & Jo Flanagan \\
\hline 4 & Simon Feasey & $\begin{array}{l}\text { Simon is an ex-primary Headteacher who now works as a } \\
\text { 'community capacity coach' using group coaching approaches to } \\
\text { bring parents and senior leaders in school into more aligned } \\
\text { working relationships. }\end{array}$ & Rebecca Tickell \\
\hline 5 & Lou Mycroft & $\begin{array}{l}\text { Lou is a 'freelance thinker' who works with a wide range of } \\
\text { organisations using the discipline of 'The Thinking Environment', } \\
\text { including for one to one coaching, group teaching and } \\
\text { facilitation. }\end{array}$ & Simon Feasey \\
\hline 6 & Rachel Lofthouse & $\begin{array}{l}\text { Rachel is a teacher educator and researcher who has previously } \\
\text { used video-based coaching approaches in research projects and } \\
\text { to support teacher development, and who has recently founded } \\
\text { CollectivED. }\end{array}$ & Lou Mycroft \\
\hline
\end{tabular}

Table 1: The six coaches in conversation with each other and their coaching contexts

The conversations were audio-recorded, and each has been listened to at least six times, both as discrete conversations and also as a combined sequence. Full transcripts have not been made, but 
on each hearing the written notes made from the conversations have been added to. While the conversations could be considered as six individual interviews, they are iterative and not conducted by a single interviewer. Contributors sometimes made reference to the conversation between other participants in their own reflections and questions. In this respect they started to share some features of a focus group. The structure allowed for equal participation between the coaches, and their responses to the overall question being triggered by questions posed by informed facilitators. Thus the data analysis has drawn on approaches common to focus group analysis.

The analysis has largely followed this sequence:

1) For each conversation individually;

a. Factual details about the nature and purpose of the coaching practice and the background and current role of the coach were noted.

b. Key dimensions of the coaching were noted using the theory of practice architecture (Kemmis et al. 2012) as an organising frame: 'doings' (the physical space) how the coaching is undertaken and how it has developed; 'sayings' (the semantic space) the language used by the coaches to describe the contexts of the coaching and the coaching practices; 'relatings' (the social space) the nature of the roles adopted and the relationships which evolve within the coaching.

2) Using the notes generated from each conversation broad themes were identified, some of which demonstrated convergence and others divergence. The conversations were then listened to as full sequences to identify the significance (or not) of these themes and to establish illustrative examples.

3) Following up a key theme of coaching being undertaken by experienced professionals working beyond their former educational roles, and of the coaching itself being formative for the coaches, the conversations were listened to again in order to identify these individual narratives.

4) The key findings of this analysis were shared with the coach participants themselves, as an opportunity to review and validate the research.

In methodological terms this research is participatory, with all coaches who were in conversation having been invited on the basis of the author's knowledge of their work as coaches, with several having contributed working papers to the CollectivED series (where relevant these are referenced in 'Findings' below). The other participants had never previously met each other, and so the conversations were borne out of a degree of genuine curiosity regarding their practices, motives and values as coaches. The conversations were framed by a broad question regarding the value of coaching in educational settings. However, as an inclusive methodology, which balanced the structured timed format and overarching question with an unstructured conversational approach with each conversation facilitated by a different participant, there was an element of trust placed in the hands of the participants that they would make a meaningful contribution.

Participants were never interrupted when in conversation and so, rather than being wedded to a specific research question, this research is perhaps best framed as a consideration of the intended purposes of a range of coaching practices in educational contexts, the natu re of those practices and the way that those practices become formative. As such the participants constructed 'the research topic by what they include[d] within the boundaries of their discussion' (Morgan, 2012, p.167). The research was not meant to be representative of all coaching in education, but is illustrative. The conversation sequence method was deliberately designed to support co-construction during the 
event. The sequence represented an opportunity for co-construction and the transformation of the knowledge and experiences held by each individual as themes that emerged in one were both intentionally and unconsciously filtered into the next conversation. The structure guaranteed that all participants were offered the chance to be listened to, to be shown respect and to have their experiences and opinions acknowledged. The unusual added element of this being conducted with an audience (of about 60 education professionals), with the knowledge that an open discussion would be evoked by the sequence of conversations reinforced this. Listening to the audio-recording for analysis revealed the extent to which this communal structure allowed what Nind and Vinha (2016) recognised as a form of praxis facilitated by dialogue between the coaches. Although not based on repeated focus groups (as described by Nind and Vinha) they appeared to come to know their work more critically through communicating their experiences in the chain of conversations, and to begin to transform their understandings of their work and themselves as coaches.

As a single method approach to research it does of course have limitations. The findings are dependent on self-report by the coaches, and are limited by the short duration of the conversations. However, the conversations emerged reflexively and avenues of enquiry were pursued which meant that to a large extent they could not be planned for. It was anticipated that multiple truths would emerge, with narratives revealing inner tensions and demonstrating complexity of coaching. The research adopts a non-positivist stance, and an interpretative paradigm, and the author (a participant in the conversations who is both a coach, coach educator and researcher) is not an objective outsider, who thus takes account of her own understandings and beliefs alongside those of the other coach participants.

\section{Findings}

This section first uses the examples of coaching shared during the conversations to consider some of the intended purposes of coaching practices in educational contexts and how these purposes translate into 'doings' or practical nature of coaching. These aspects are further explored through noting the specific language adopted in the conversations, or 'sayings', related to the context within which coaching happens and how coaching conforms to or offers an alternative to this context. Following this there is a consideration of the 'relatings' underpinning the coaching approaches, highlighting who is involved and on what basis, the roles taken in the coaching process and how these can be modified through the coaching cycles. Within this discussion attention is given to narratives offered by the coaches about how they became, and then changed, as coaches. Framing the analysis through both the Kemmis et al's (2012) theory of practice architecture (doings, sayings, relatings) and the exemplar narratives has allowed core themes to emerge and these will be further explored up in the discussion session.

\section{Commonalities and contrasts in coaching}

Each of the coaching approaches described in the conversations were nuanced to suit specific contexts and purposes. While most focused on one-to-one coaching, there are also practices which drew groups into coaching conversations. Having said this there were a number of similarities which are noteworthy. The most significant common factor was the expectation that the coach and coachee(s) would enter into dialogue, and that this dialogue would create the opportunities for something to be learned or changed as a result. Ruth, for example, worked with her teaching colleagues over a period of time with the intention of developing their teaching repertoire (Whiteside, 2017). Simon worked at the interface between school staff (often those in leadership roles) and the wider school community (most commonly parents), having been commissioned to help them form more authentic and informed partnerships (Feasey, 2017). Jo's work as a specialist 
coach, deployed her knowledge of speech, language and communication development and delay to support teachers to enhance their pedagogic approaches to benefit learners (Flanagan et al. 2017, Lofthouse et al. 2018). When the author had first acted as a coach it was within a research project exploring how teachers could be supported to develop their teaching practices to enhance metacognition (Lofthouse, 2018). In each case the coach found themselves striking a balance between the agenda of the organisation or project and the motives and interests of their coachees. This is particularly the case where coaches were commissioned as external experts, or where they were employed in a specific role to which they are accountable.

Another commonality is that the coaching had structures or protocols underpinning it, which Hargreaves and O'Connor (2018a) propose as a key principle for joint work. All of the coaches in this study adopted their own particular approach, using specific tools or organisational structures, but in each case there was a routine. These structures (though different between coaches) seemed to be more than habits that had been fallen in to over time, and had been developed in a disciplined way by each coach in practice. Two coaches (the author and Jo) used a three part repeated coaching cycle, which included discussions to co-plan with the coachee prior to lessons, the coach observing and videoing lessons allowing shared review of teaching and learning and a professional discussion following the lesson. Lou explicitly used the discipline of the Thinking Environment (Kline, 2009) with the ten components of 'place, equality, encouragement, attention, appreciation, ease, diversity, information, feelings and incisive questions' underpinning her coaching (Mycroft and Sidebottom, 2017). After initial conversations with the commissioning school leaders Simon organises a meeting solely for members of the community (without school staff present), and uses a group coaching approach to elicit their concerns, interests and perspectives. In two cases the narratives offered by the coaches also indicated how their approaches had changed over time. Rebecca, who had had prior experience of the GROW model of coaching (Whitmore, 2002), found that developing transformational and developmental coaching, based on her ILM coaching training, forced her to be more disciplined to adopt a listening mode, and that this allowed her to use a more powerful questioning technique, often just evoking more reflection by asking 'and?'. Having initially adopted a one-to-one coaching approach with her teaching colleagues Ruth had started to implement the routines of lesson study (Dudley, 2015) so that the coaching conversations that occurred were more peer focused.

\section{The discourses of coaching}

In terms of their identity there was variance in how the conversation participants described themselves. Despite not equally self-identifying as 'coaches' all of the participants said that they did coach in their professional roles. Jo, Ruth and Rebecca claimed the term 'coach' as part of their professional identity, although Rebecca also discussed how mentoring and coaching often came together in educational settings. Lou described herself as a 'freelance thinker', but did state that she adopted a coaching mode of the Thinking Environment where that was a suitable approach. Simon questioned whether he was a coach, but had alighted on the term when dismissing the terms 'advisor' and 'consultant' to describe his new freelance role, and recognised that he drew on coaching approaches in his work. The author had been a designated coach in the past, but now worked in other academic roles (including researching coaching), while believing that she often drew on a coaching repertoire and values when working with colleagues and teaching or supervising students. 
During their conversations the coaches often described the professional contexts in which they coached. In some instances, there was an apparent stark problem in the setting which it was anticipated the coach would help to address. The school that Ruth was newly employed in with a coaching remit, was described as being 'in crisis' and had experienced a 'painful' external review which drove the senior leaders to 'impose' new professional expectations and routines, and she also recognised that being employed in this role meant that for some time teachers she was directed to teach saw her as 'part of the problem'. The headteachers who recruited Simon as a community capacity coach often framed their request as 'what can we do about a specific [this] problem with [these] parents?'. In other instances, a specific pedagogic developmental opportunity had become apparent, such as where Jo used her speech and language expertise in inter-professional coaching to support teachers to 'sharpen up their practice'. There is a sense that coaching is often being used in an attempt to 'close the gap', both in terms of pupil outcomes and teacher performance and repertoire.

In describing their coaching several of the conversation participants were at pains to say what coaching was not. Rebecca recognised her own professional tendency to want to 'help or save people' and to act in an 'advisory' capacity, but she went on to say that this is not what coaching is about. Simon resisted the expectations of many headteachers to have his work dominated by their side of the story and to find a quick fix to their perceived problem, by inviting members of the community to a meeting in which a coaching approach was used to elicit wider perceptions. He tried to steer both the senior leaders and community away from the irritating details that concerned them to generate shared values and commitment to a common ambition for the school. Similarly, Jo had become conscious of the performative aspects of school cultures (Ball, 2003), and how these could invade coaching spaces (Lofthouse and Leat, 2013), and thus was careful not to promise that coaching would create a rapid improvement in pupil outcome data.

Analysis of the conversations did reveal noteworthy similarities in how coaching was described. It is important to recognise that these are self-reports, and the sequence of conversations may have led to accumulated bias, but strong overlaps were indicated. Coaching was described by the contributors as creating a space where the coaches 'listened to' and were 'attentive to' their coachees, allowing them to 'open up' and to 'do their best thinking'. Coaching allowed both coach and coachee to 'share', 'learn' and 'find solutions' through their participation, with an expectation that dialogue would be both 'exploratory' and 'reciprocal'. These aspects form the basis of the 'relatings' which will be further considered below. A final commonality which threaded through the conversation was the fact that coaching was seen as an 'authentic' process, one which was 'embedded' in 'real' educational settings, and allowed a 'bespoke' approach to foster development and change.

\section{Coaches in formation}

When constructing an original research question regarding the scope and impacts of coaching it was not anticipated that the conversations from which the data was drawn would include significant details of the coaches' transition into their roles and the ways that they had developed their coaching practice over time. However, as the conversations emerged these aspects were revealed and thus form part of the findings. While each case is unique these narratives again reveal interesting similarities. To do these justice elements of each participants' story have been constructed here as vignettes, drawn from repeated listening to the audio-recording of the conversations. These vignettes were developed by focusing on professional biographical details 
which were extracted from the recordings alongside specific accounts of how these influenced current coaching practices.

Simon

Simon is a former primary Headteacher and Deputy Headteacher in two schools and in those roles was always most interested in forging positive relationships between the schools, their communities and pupils' parents, prioritising this during his work days and frequently taking the bureaucracy of the job home in the evenings. Prior to leaving his last headship Simon commenced a doctorate focusing on relational approaches to school leadership. Simon is now developing his practice as a freelance community capacity coach, and has worked as such for various schools across the UK. Simon describes his work as having the potential to liberate people and set them free to empower schools and communities to work together.

Ruth

Ruth is an experienced teacher and has been a member of schools' senior leadership teams (SLT) in three schools. She was 'head hunted' for her current role and on appointment two years ago was given the remit of coaching staff to improve their teaching performance and pupils' outcomes. Prior to taking up this role she had completed the taught modules of a Masters in Education which included a focus on coaching and mentoring, and culminated in a dissertation which researched her experiences as a coach in her former and current school. In her role as coach Ruth recognised that not all her SLT colleagues shared the same concept of what coaching would involve, and she was initially swept up with a performative approach in which coaching was 'done to' teachers who were underperforming. Over time she has managed to gain more teachers' trust and buy in and has recently begun to develop a more collaborative peer-coaching approach based on lesson study.

Lou

Lou has worked in public health, community development and teacher education, and now works as a 'freelance thinker'. She has used the Thinking Environment as a multi-modal approach underpinned by key values in a range of contexts for 25 years. She reflects on how the discipline of this approach allows her to be her 'best self' in her work (including coaching), and to evoke other people to do their best thinking. She contrasts this discipline with her personality which is impulsive, but her experience has taught her that freedom to think needs boundaries.

Jo

Jo worked as a speech and language therapist spanning health and education for 20 years with a particular focus on children. Five years ago she set up her company with her colleague Bib with the desire to develop 'another way' to support children's speech and language development and enhance their educational experience and outcomes. In their past work they had used video-based interventions (for example with parents) and they have gone on to collaboratively develop a videobased teacher coaching approach, which sits alongside more traditional CPD. As a means of developing the coaching approach Jo and Bib worked collaboratively with an academic-practitioner with expertise in teacher coaching. Jo describes the coaching work as one in which experiences, knowledge and skills can be shared reciprocally across the professional boundary, with cumulative effect over time.

Rebecca

When Rebecca made the transition from teacher and senior leader to working in a university-based school leadership development centre she was invited to undertake professional development to gain an Institute of Leadership and Management coaching qualification. As part of her practice she decided 
to coach employees in a business context as means of developing her own practices in a new environment which she described as out of her comfort zone. Powerful lessons learned included the value of being a coach external to the coachees' organisation, and thus bringing no agenda to the conversation and not being in a position to make judgements, as well as the need to resist filling the silences in coaching conversations. This helped her to deconstruct her previous experiences as a mentor and of using the GROW coaching model, and to adopt coaching approaches which focused on supporting self-efficacy.

The vignettes offer illustrative insights of the ongoing journeys to becoming coaches and further insights into the roles of coaches. While it cannot be stated that these are fully representative of coaches working in education settings the narratives afford some analysis. The development of these coaching practices often coincide with new employment (or self-employment) opportunities and engagement with professional scholarship. The use of coaching in the educational setting is also often sought as a new approach to an existing issue. However, these coaches typically bring a wealth of expertise and experience to their role, even as new coaches themselves. They go on to experience coaching as itself a formative process, one through which they learn more about themselves, the educational contexts, dilemmas and opportunities and of their own skills and capacity for coaching. Coaching in education is not a static practice with a pre-determined and acquired skills set, but one which seems to evolve over time.

\section{Coaching as relational practice}

When analysing the conversations between the coaches with respect to the 'doings', 'sayings' and 'relatings' (Kemmis et al. 2012) it was apparent that the latter aspect had generated the most discussion. This itself suggests that the coaches see coaching as fostering a distinct (but sometimes hard won) quality of social space in the architectures of professional development in education settings. The vignettes and information in table 1 outline who acts as coaches and who participates in coaching in our examples, and it is also clear that there are often gatekeepers (usually senior leaders), who give permission for, or even seek out the coaching approach for their staff or school communities. This commissioning process combined with the level of experience, expertise and former professional roles held by coaches has the potential to create a power imbalance in the coaching relationships themselves, particularly where coaching is intended to close a gap.

The coaches in this study were aware of that, and it sometimes took some time to overcome that power imbalance and to create a more comfortable and productive working relationship with their coachees. As Jo said, 'we started off thinking we were going to be the specialists [...] but it's been a very different process where we come to solutions together [...] we share our expertise'. Ruth, Jo and Simon all found themselves needing to spend time reframing the urgency of the expectations of the impacts of coaching in the minds of senior leaders. In all our cases the coaching processes were adapted over time to create a sense of inclusion. Simon offered the following insight 'it means interrogating relational power and trust', illustrating this with a memory of an early meeting with parents where they persuaded him to change the terminology used to describe the group to one they could identify with.

Effective coaching relationships were seen as those where the coach and coachee came together to discuss the genuine concerns and practices of the coachee, often by revealing evidence from that context not previously brought to the fore. Video helped to achieve this, as did the quality of attention offered through The Thinking Environment, the willingness of the coach to let the participant(s) open up and be heard through honing their listening skills, and the ability to create a 
non-judgmental space. This was achieved in part by building trust over time and maintaining confidentiality. The coaching space is deemed to be one in which it is safe to feel vulnerable, to reveal what causes tensions or uncertainty and where disconnects (e.g. between pedagogic practice and research) can be explored. Several coaches indicated that what occurred in their most successful practice was co-construction, where ideas were generated in that moment, related closely to the shared knowledge of the context, drawing on the contributions of both the coach and coachee and being built on cumulatively through the coaching process. There was also a sense that while effective coaching relied on these relational characteristics it can also itself generate them, offering evidence of the value of coaching as a process which is sustained over some time, rather offered than an interim or short-term CPD measure.

A further aspect of the 'relatings' dimension of coaching revealed through the conversations was the relationship between the coaches' personal values and their professional practices as coaches. While this was inherently intrapersonal it translated into the interpersonal domain. Lou and Simon perhaps best illustrated this, with Lou explaining that her work in the Thinking Environment was 'completely congruent with [her] values as a teacher educator' and that consequently this work had 'brought [her] ease', and Simon explicitly linking the priorities he had established for himself as a headteacher and parent and the values and 'passion' he brought to working with communities and parents, in which he helped them to explore vulnerability and power through exploratory dialogue, often leading to 'breakthrough' moments. Ruth was particularly pleased recently when a teacher invited her to come in and observe a lesson because she was so excited to be trying something out and wanted to share it; not only because this was a way in to working with her colleague, but because it mapped onto the personal values that underpinned her coaching as wanting to create a positive environment for peers to develop together.

\section{Discussion}

The illustrative cases of coaching revealed by this research confirm Bloom et al.'s (2005) contention that coaching is not easily defined, in that intended purposes or organisational features of coaching practices in educational contexts are not uniform. However, while the specific foci for coaching varies in the included cases it is possible to suggest some broad cultural norms of coaching.

One such norm is that coaching can be practised in a way which acts as a counterweight to the performativity agenda in schools, while still existing within it. There is a fine and dynamic balance being struck. Where coaches are enrolled to 'close the gap' in pupil or teacher performance this can reinforce the performative agenda with the risk that Lofthouse and Leat (2013) drew attention to with the risk of undermining the potential benefits of coaching. Evidence from analysing the conversations between the coaches in this research does however indicate that if coaching relationships are given time to develop, and if the coach's understanding of educational contexts is nuanced enough, the practice of coaching can be more than an instrumental process. In all the profiled cases there was limited desire on the coaches' parts to 'tell to', or to 'tell how to' change their coachees' practices, even when that was directly or indirectly expected by the gatekeepers, usually the senior leaders. Instead coaching created opportunities for co-construction (Lofthouse et al., 2010) and this could happen even when coaches were bringing distinct expertise to the coaching partnership. As such it might be suggested that coaching has the potential to enable the first tenet of collaborative professionalism suggested by Hargreaves and O'Connor (2018), that of 'collective autonomy' through which educators are more independent of top-down administrators and school 
leaders, but have less independence from each other. In this way, they suggest that teachers 'are given or take authority' (p.24).

Co-construction is a dialogic process, and relies on trust (as recognised by Whitmore, 2002 and Tschannen-Moran and Tschannen-Moran, 2010). Trust cannot be expected to be in place at the start of coaching episodes, and indeed an imposition of coaching can cause a loss of trust or feeling of exposure. However, trust but can be generated over time through the quality of the relationships that the coaching participants form, as attention is offered allowing vulnerabilities to be revealed, and tensions explored in non-judgemental spaces. Good practices in coaching can sustain the participants' collaborative generative attention and thus create an environment for professional learning and change. Coaching may be a 'malleable' form of CPD as defined by Kennedy (2014), but when practised beyond the performative constraints can also be considered as meeting the criteria she uses to define 'transformative' CPD. This is because coaching can create an environment of 'collaborative professional inquiry' characterised by 'collaborative problem identification and subsequent activity, where the subsequent activity involves inquiring into one's own practice and understanding more about other practice' (Kennedy, 2014 p.693). Through this process coaching can contribute increased professional capacity into the education system, and this might be interpreted as increasing collective efficacy. While acknowledging that coaching might increase teacher collective efficacy (Donohoo, 2017), with the potential to enhance student attainment, through the examples of coaching illustrated in this research it is also possible to conceptualise collective efficacy as being potentially constructed both inter-professionally and between the community and its school.

An alternative theorisation is that coaching can play a role in teachers and others in education 'achieving' agency because it can contribute to ecological agency. Priestley et al. (2015) view agency an emergent phenomenon, with three temporal dimensions; being heightened by a wide repertoire of past experiences, being future-facing and enhanced when multiple future possibilities can be articulated and explored, and with decisions being enacted in practice in the here and now, accommodating the limitations of the context, but applying informed judgements about what is possible. The coaches' narratives indicate that these are a group of professionals who have high levels of self-awareness and self-regulation and who are able to align their coaching practices with existing expertise and their personal and professional values. While they might not be representative of all coaches adopting similar roles these attributes are still worth acknowledging. These coaches are able to focus on their coachee's situation while bringing to bear their expertise from former professional roles and of coaching practices, to help the coachee to develop agency to meet the dilemmas they face in practice.

As the concept of 'collaborative professionalism' offered by Hargreaves and O'Connor (2018a) is a relatively new one, it may be too early to propose that coaching might be one of the tools needed to achieve it. Having said this, they do refer to teachers mentoring and coaching each other in Columbian networks of schools, using this as an example of to illustrate 'joint work' which is 'thoughtful work that involves dialogue as well as doing' going on to state that in collaborative professionalism 'talk is part of the work' (Hargreaves and O-Connor, 2018a, p.160). Hargreaves and O'Connor (2018b) further explore the conceptualisation of collaborative professionalism, recognising that 'not all collaboration is equally effective' (p.20), and drawing attention to the degrees to which the work can be characterised as having different degrees of solidarity and solidity (substance). They reinforce this about by stating that 'collaborative professionalism is about integrating relationships and rigor' (p.23). As van Campbell and Nieuwerburgh (2017) make clear, coaching in education is not simply about meeting the perceived needs of the coachee, but needs to have a clear 
link to addressing desired educational outcomes for their students or colleagues (depending on the coachee's role). So creating strength through the 'relatings' (Kemmis et al. 2012) is just part of the coaching in education jigsaw, and relevant 'solid expertise' (Hargreaves and O'Connor, 2018b, p.21) is critical too. Perhaps this is what Rebecca meant when she said in her conversation that 'I think in a teaching context, coaching and mentoring come together and they mesh'. This research offers insights into how coaching can be seen as a valuable way of retaining skilled and knowledgeable practitioners within the education system to work in new roles for the benefit of others in that system. The fact that these coaches were conscious that their own coaching was constantly in formation, does suggest that this it can be a reciprocal and cumulative relationship. The conversational structure from which the data for this research was drawn could be seen as mirroring effective coaching, as in both cases 'reflective dialogue result[s] in different forms of knowledge emerging' (Moyles et al. 2002, p.472).

\section{Conclusions and implications}

The research is indicative of how coaching can contribute to the professional development landscape for teachers and others in education. It generates themes such as the role of informed, professional expertise in educational coaching (in addition to expertise in coaching per se) which would be worthy of further, scaled up research. The coaches whose conversations were analysed had all worked in relevant fields for at least twenty years before, or during which, they had developed their coaching practices, and further research could investigate how common this was amongst coaches, and whether that kind of experience and maturity influences coaching approaches, and how this then impacts on coachees. This may be particularly relevant in the UK given the current promotion of coaching and the burgeoning social media presence of coaches in a largely privatised and unregulated CPD landscape.

The coaches all described certain disciplines, structures, protocols or tools that they used to scaffold their coaching. Further research could explore the extent to which these can be successfully adopted by other coaches, and whether these tools are always facilitative or might become constraining. This research, while drawing on dialogues, only offers the perspective of the coaches. It would be interesting to deploy the same conversational thread approach to hear the experiences and views of a number of coachees. Do they feel the same benefits and tensions as the coaches; do they also recognise successful coaching relationships as being built on solidarity and trust, or are the coaches forming a distorted view of their own practices? Finally, there is a strong sense that the relational aspects of effective coaching can create a social space in which teachers and others in the education system can feel heard and valued, and where their knowledge and skills are brought to the fore to be worked with and extended through co-construction. This may support a teachers' sense of belonging and confidence in educational settings, even when they are challenging. With the current concerns over teacher retention, wellbeing and stress this relational aspect may be worthy of further research.

While acknowledging that this is research leads on to many more questions, it does provide additional weight to the argument for more good coaches to be available to support more teachers, leaders and school communities. There seems little doubt that creating sophisticated and flexible education systems requires what Lou called 'the best thinking we can do'. Good coaching practices can play a part in those contributing to the system achieving this. 


\section{References}

Ball, S. J. 2003. The teacher's soul and the terrors of performativity, Journal of Education Policy, 18 (2) $215-228$

Bandura, A. 1997. Self-efficacy: The exercise of control. New York: Freeman.

Bloom, G., Castagna, C., Moir, E. and Warren, B. 2005. Blended Coaching: Skills and Strategies to Support Principal Development, Corwin Press, Thousand Oaks, CA.

Campbell, J. \& van Nieuwerburgh C. (2017) The Leader's Guide to Coaching in Schools, Corwin Press, Thousand Oaks, CA.

Clutterbuck, D. 2001. Everyone needs a mentor (London, Chartered Institute of Personnel and Development).

Donohoo, J. 2017. Collective Efficacy: How Educators' Beliefs Impact Student Learning, Corwin Press, Thousand Oaks, CA.

Dudley, P. 2015. Lesson Study: professional learning for our time. London: Routledge.

Feasey, S. 2017. Community capacity building coaching, CollectivED, (1) 43-45, Carnegie School of Education, Leeds Beckett University

Flanagan, J., Wigley B. and Lofthouse, R. 2017. Developing the use of communication rich pedagogies in classrooms using Video Enhanced Reflective Practice informed methodologies as a vehicle for teacher and speech and language therapist continuing professional development.

Attuned Interactions, (3)

Hargreaves, A. and O'Connor, M. 2018a. Collaborative Professionalism: When Teaching Together Means Learning for All, Corwin Press, Thousand Oaks, CA.

Hargreaves, A. and O'Connor, M. 2018b. Solidarity with solidity: The case for collaborative professionalism, Phi Delta Kappan, 100 (1) 20-24

Joyce, B. and Showers, B. 1988. Student Achievement Through Staff Development, Longman, New York,

Kemmis, S., Edwards-Groves, C., Wilkinson, J. and Hardy, I., 2012. Ecologies of practices. In: P. Hager, A. Lee, and A. Reich, eds. Learning and practice. Dordrecht: Springer

Kennedy, A. 2014. Understanding continuing professional development: the need for theory to impact on policy and practice, Professional Development in Education, 40 (5), 688-697

Kline, N. 2009. More Time to Think. Fisher King, Burley-in-Wharfedale.

Lofthouse, R. 2018. Long live metacognition, lessons learned from a life in the field, CollectivED, (4) 70-76, Carnegie School of Education, Leeds Beckett University

Lofthouse, R., Flanagan, J. and Wigley, B. 2018. Talking it through: Using specialist coaching to enhance teachers' knowledge from speech and language sciences. Impact: Journal of The Chartered College of Teaching, (2) 85-88.

Lofthouse, R. and Leat, D. 2013. An Activity Theory Perspective on Peer Coaching. International Journal of Mentoring and Coaching in Education, 2 (1) 8-20.

Lofthouse, R., Leat, D. and Towler, C. 2010. Improving Teacher Coaching in Schools; A Practical Guide, CfBT Education Trust

Lofthouse, R., McElwee, S., King, C., Lofthouse, C. 2017. Lesson Study: an opportunity for collaborative teacher inquiry, in Teachers and Teacher Educators Learning Through Inquiry: International Perspectives, The Jan Kochanowski University, Kielce, Poland

Lofthouse, R. and Thomas, U. 2017. Concerning collaboration; teachers' perspectives on working in partnerships to develop teaching practices. Professional Development in Education, 43 (1) 36-56.

Morgan, DL. 2012. 'Focus groups and social interaction', in Gubriem, JF., Holstein, JA., Marvasti, AB., McKinney, KD. (eds). The Sage Handbook of Interview Research: The complexity of the craft. Sage, Thousand Oaks, CA. 161-176

Moyles, J., Adams, S. and Musgrove, A. 2002. Using Reflective Dialogues as a Tool for Engaging with Challenges of Defining Effective Pedagogy. Early Child Development and Care, 172 (5) 463478. 
Mycroft, L. and Sidebottom, K. 2017. Using thinking environments for emancipatory coaching practice. CollectivED, (1) 19-21, Carnegie School of Education, Leeds Beckett University

Nind, M. and Vinha, H. 2016. Creating interactions with data. Using visual and metaphorical devices in repeated focus groups. Qualitative Research, 16 (1) 9-26.

Priestley, M., Biesta, G. and Robinson, S. 2015. Teacher Agency; An Ecological Approach. Bloomsbury, London

Simkin, T., Coldwell, M., Caillau, I, Finlayson, H. and Morgan, A. 2006. Coaching as an in-school leadership development strategy: experiences from Leading from the Middle, Journal of InService Education, 32 (3) 321-340.

Tschannen-Moran, B. and Tschannen-Moran, M., 2010. Evocative Coaching. 1st ed. San Francisco: Jossey-Bass.

Veenman, S. and Denessen, E. 2001. The coaching of teachers: results of 5 training studies, Educational Research and Evaluation, 7 (4) 385-417.

Whiteside, R. 2017. Is coaching for transformation possible in a culture of performativity? CollectivED, (1) 5-9, Carnegie School of Education, Leeds Beckett University

Whitmore, J. 2002. Coaching for performance: GROWing people, performance and purpose (London, Nicholas Brealey). 